\title{
Assistive Technology at the University of Tennessee -Chattanooga: Providing Pre-service Educators with the Opportunity to Utilize Assistive Technology as an Instructional Strategy
}

\author{
Tiffani Kay Crider, Linda Johnston, Valerie Rutledge, Amy L. Doolittle, Larry Beard* \\ Department 4154, 615 McCallie Avenue, Chattanooga, TN 3740 \\ *Corresponding Author: 1beard@jsu.edu
}

Copyright (C) 2014 Horizon Research Publishing All rights reserved.

\begin{abstract}
With the legal mandates described in the Amendments to the Individuals with Disabilities Education Improvement Act Amendments (IDEIA) of 2004 and the No Child Left Behind Act (NCLB) of 2001, educators must meet the needs of all students in their inclusive classrooms. Today's diverse classrooms include students with a wide range of abilities. The rise in diversity of America's classrooms makes differentiation, accommodating, and modifying instruction imperative for learner success. Assistive technology (AT) is at the forefront of services for students as a means to meet the individual needs of students when appropriate. The key to teacher and student success is training and knowledge of the educators as it relates to the implementation of AT. This begins with educators at the pre-service level. University teacher education programs must take the necessary steps to ensure their graduates are equipped with the skills needed to make instruction effective for all students. This process can not be done without the proper background knowledge and training in the area of AT.
\end{abstract}

Keywords Assistive Technology, UTC, Pre-Service Education, Special Education, Assistive Technology Training, Teacher Training

\section{Introduction}

Assistive Technology was first defined as part of the Technology-Related Assistance Act of 1988 (PL 101-407). Commonly known as the Tech Act, it defines AT as an item or piece of equipment or product system either acquired commercially, off the shelf, modified, or customized and used to increase, maintain, or improve functional capability for an individual with disabilities (Carpenter, Johnston \& Beard, in press). According to the Act, these services include;
1. evaluation of needs, providing for the acquisition of assistive technology devices by individuals with disabilities;

2. selecting, designing, fitting, customizing, adapting, applying, maintaining, repairing, or replacing, such assistive devices;

3. coordinating and using other therapies, interventions, or services with assistive technology;

4. training or providing technical assistance for an individual with disabilities; and,

5. training or providing technical assistance for professionals, employers, or other individuals who provide services to or are otherwise substantially involved in the major life functions of individuals with disabilities(IDEIA, Public Law 100-407).

This definition continues to be the one that individuals refer to when making decisions regarding appropriate AT use.

AT tools range from light tech modifications such as pencil grips, to high tech modifications such as software, tablets, smart phones and motorized equipment. These devices have the potential to and intention of enhancing access, inclusion, productivity, and the quality of life of individuals with disabilities (Chmiliar and Cheung, 2007).

\section{The Need for AT Training: Legal Mandates for Pre-service Educators}

Educational mandates present challenges to education professionals in the use of AT in classroom settings with students who are at risk and/or have developmental disabilities (Parette, Stoner, and Watts, 2009). For students with disabilities, federal regulations require that the decision as to whether a student requires $\mathrm{AT}$ as part of their educational programming be made by their Individual Education Plan (IEP) Committee. According to the 
Individuals with Disabilities Education Act Amendments of 1997 (IDEA, 1997), the student's IEP team must consider the use of AT as part of the planning process. The most recent amendments to the Individuals with Disabilities Education Improvement Act (IDEIA, 2004) continue to require that educational teams consider whether the child needs AT devices and services. Amendments to Section 508 of the Rehabilitation Act of 1998 and the Americans with Disabilities Act of 1990 also have these mandates. These mandates all stress the need for professionals to develop adequate competencies for providing effective services to those requiring AT devices and services.

Few educators are adequately prepared to use technology themselves, much less to teach and help students in the use of technology. "Thus, we need to enhance present technology pre-service to further integrate technology in today's schools" (Manning and Carpenter, 2008, p. 48). There is a need to integrate technology in all education courses. Some contend that all pre-service teachers need to learn how to create and modify the educational experience for students who have learning disabilities (NJSLD, 1998; Howell, 1996). Such modifications must include the use of AT devices to help develop and support a collaborative teaching environment that provides all students with educational experiences that enable them to maximize their potential.

American's classrooms are a haven for diversity, and teachers need to be equipped with various tools to meet the individual needs of each student. Due to inclusion, the number of students with disabilities in the general classroom is on the rise, thus presenting both general educators and special educators with the need to increase their knowledge and strategies in the selection and use of AT. In addition, the number of ELL students in the US has risen to over 5,000,000 (NCELA 2007). With the numbers on the rise the accountability measures enacted by federal legislation and the need for differentiation and individualization, AT is a means by which teachers can use to deliver instruction. Students benefit from the visualization of words when learning to speak a new language and AT software programs geared to provide visualization of words in several languages can be utilized. But we will need to train pre-service educators in different strategies, including hardware and software applications, to meet the needs of all students. Pre-service students will require a strong knowledge base of AT as one of the strategies pre-service teachers will need to help differentiate instruction. This begins with higher education taking the lead to ensure teachers in all curriculum areas are adequately trained (Lahm, 2003).

Puckett (2002) conducted surveys and studies on this very issue of teacher training in AT. The results included the following:

1. a need for improvement in teacher knowledge, confidence, and willingness to use AT in lesson plans;

2. the need for hands-on training and support in implementing AT, and;

3. the necessity of ready access to software and equipment for instructional purposes.
In her study, over $90 \%$ of teachers reported limited knowledge of voice activated word processors, text reading programs, and programs to support transcription and sentence generation. According to Judge and Simms (2009), pre-service students should not only receive more instruction in AT, but also receive critical components of technology training, including practice and feedback when AT instruction is infused and modeled across all courses and all instructors.

\section{The Role of Higher Education}

Judge and Simms(2009) conducted a survey of over 185 different undergraduate licensure programs in special education. Of these 185 programs, only $34.6 \%$ had a mandated AT course for the degree and licensure requirements. The training was at a basic level, exploring only what devices is available. Courses must also show educators how to use the devices, as well as teach what the best practices are for instruction in the utilization. In addition, updated and current software must be demonstrated to candidates, as well as provide them with the opportunity to embed AT as part of the modifications and accommodations when doing lesson planning.

Lahm and Sizemore (2002) recommend that Individual Education Plan (IEP) teams be multidisciplinary in their composition. Utilizing the IEP model and incorporating this as one area of AT training is a starting point for undergraduate programs. This is currently introduced in the overview of exceptionalities in most teacher training programs. Faculties within teacher preparation programs must also look at state standards and begin incorporating AT as a means to deliver instruction related to particular standards.

Diverse classrooms often present teachers with opportunities and sometimes challenge them as to the types of instruction to meet individual needs. Traditional classroom teachers oftentimes teach to the middle with accommodations and modifications being made at either end of the achievement spectrum (Morrison, 2007). Training pre-service educators to think about and utilize AT is one means of closing the achievement gap when thinking about delivery of instruction.

\section{AT@UTC}

Candidates seeking licensure in all education programs at the University of Tennessee at Chattanooga (UTC) are instructed in depth in the use and selection of AT during the Professional Development (PDS) I semester. UTC has received an AT grant from the state for the past 5 years to purchase software for the purpose of training pre-service educators in the appropriate use and selection of AT, both light and high tech. In the beginning, faculty met and determined there was a need to implement AT within various 
programs and specifically targeted courses in each area.

The faculty were trained by the AT Adaptive Coordinator in the Office for Students with Disabilities (OSD) to provide a demonstration and hands-on opportunities for candidates to become familiar with various AT software programs and devices. Both the AT coordinator in the OSD and the instructor of the PDS I candidates received their Assistive Technology Applications Certifications through the California State University Northridge Center on Disabilities.

The candidates who are enrolled in the PDS I semester, must go through intense training on the use of AT. The knowledge must then be applied in the development of their unit under the modifications and accommodations section. Candidates follow an outline developed by the instructor for the modifications and accommodations in selecting appropriate AT to individualize the lesson for students with a diagnosed disability, ELLs and students who are at risk for dropping out of school. The NCES (2007) documents 8.7\% of the population ages 16-24 were not enrolled in high school and lack a high school credential. This statistic alone substantiates the need for the use of AT as one strategy to differentiate instruction in an effort to provide students with the opportunity to be successful and remain in school.

Candidates who have the opportunity to learn and embed AT within their lesson planning often utilize AT during their student teaching semester. The AT software is available for use by UTC students, and the AT Adaptive Coordinator and faculty are available to guide candidates in the selection of appropriate use of AT based on the needs of the students. All candidates have access to the software that is on each computer within the computer lab and also through the OSD.

The faculty, AT specialist and AT adaptive coordinator provide updates, information and demonstrations to PDS I candidates at the beginning of the semester as an introduction. In addition a seminar at the beginning of student teaching as a reminder that $\mathrm{AT}$ is an outstanding option for differentiation of instruction for many students, depending on their needs. Candidates also utilize AT in their unit development during the student teaching semester.

The AT grant has provided UTC with a means to not only purchase software but to engage candidates in the use and consideration of AT as an option for students with disabilities, ELLs and students at risk for dropping out of school. This has been and continues to evolve as a means for meeting the individual needs of all students as well as provide them with an opportunity to access the general education curriculum.

\section{Challenges/Barriers}

There are many challenges facing educators and universities regarding AT instruction. "Challenges continue to exist for teacher educators to implement AT curriculum within courses, because existing courses are already filled with other essential knowledge and skills" (Manning and
Carpenter, 2008, pg.47). Teachers are often informed of the importance of using AT and regular technology in the classroom. However, very few teachers are given training on what devices are available for them. Still, with the current legal responsibilities and increasing need, fewer than half of the universities surveyed by White, Wepner, and Wetzel in 2003 said they had a course dedicated to AT. Morrison (2007) found that the main barrier concerning teachers with AT is their lack of training in this area. Sparks(2006) reports that only $7 \%$ of schools have teachers who are skilled enough in the use of technology to effectively integrate it into their lessons. In spite of this obvious need, Lawless and Pellegrino (2007) report that $36 \%$ of schools provide no professional development for technology and another $29 \%$ provided only 1-14 hours of training per year. The lack of training results in a low comfort level when using AT. Morrison also stated that it is difficult to find qualified personnel to complete training, assessments, and recommendations for AT.

\section{Conclusion/ Summary}

Educators must meet the needs of all students. As a nation, we can no longer allow students to fall behind. The infusion of AT content into courses in special education programs has been advocated but is often difficult. If programs do incorporate AT into the curriculum, it is one of two ways: 1) through a basic overview of AT in an introductory course(s); or 2) it is the decision of each instructor as to how in depth this is done (Judge and Simms, 2009). Huge advances in AT have been made over the last decade. However, much is yet to be accomplished. It is up to all educators to help others understand the benefits that AT devices have to offer to all students. Universities must do their part in order to prepare future teachers for this service.

Successful AT implementation at the student level requires more than just upgrading teacher preparation courses at the post-secondary level. Collaboration is required within a number of organizational units and various disciplines. "The provision and implementation of AT requires the involvement and services of a number of professionals in a multidisciplinary team" (Chmiliar and Cheung, 2007, p. 19). A workable knowledge of AT is needed by all individuals involved in making decisions about the implementation of AT. Professional development should expand beyond the in-service educator to the pre-service level.

\section{REFERENCES}

[1] Amendment to Section 508 of the Rehabilitation Act of 1998 (1998). Retrieved October 15, 2013 from http://www.section508.gov/index/cfm?FuseAction=Content $\& \mathrm{ID}=3$. 
[2] Americans with Disabilities Act (1990) 42 U.S.C.A. $\$ 2120$.

[3] AT @ UTC 2010. Grant written for the University of Tennessee at Chattanooga

[4] Beard, L., Johnston. L., \& Carpenter, L. (2010).Assistive Technology: Introduction, Overview, and Ethical Standards of Practice. In Assistive Technology: Access for all students. Pearson: Upper Saddle River, NJ.

[5] Carpenter, L., Johnston. L., \& Beard, L. (in press).Assistive Technology: Introduction, Overview, and Ethical Standards of Practice. In Assistive Technology: Access for all students. Pearson: Upper Saddle River, NJ.

[6] Chmiliar, L., \& Cheung, B. (2007).Assistive technology training for teachers-Innovation and accessibility online [Electronic version].Developmental Disabilities Bulletin, 35(1), 18-28.

[7] Howell, R. (1996). Technological aids for inclusive classrooms. Theory Into Practice, 35(1), 58-65.

[8] Individuals with Disabilities Act (1988).Pub. L. No. 100-407.

[9] Individuals with Disabilities Education Act Amendments (1997).Pub.L. No. 105-17.

[10] Individuals with Disabilities Education Improvement Act (2004).Pub. L. No. 108-446.118 STAT. 2647.

[11] Judge, S., \& Simms, K. A. (2009). Assistive technology training at the pre-service level: A national snapshot of teacher preparation programs [Electronic version]. Teacher Education and Special Education, 32(1), 33-44.

[12] Lahm, E.A. (2003). Assistive technology specialists. Bringing knowledge of assistive technology to school districts. Remedial and Special Education24(3), 141-154.

[13] Lahm, E. A., \& Sizemore, L. (2002). Factors that influence assistive technology decision-making. Journal of Special Education Technology, 17(1), 15-26.

[14] Lawless, K.A., \& Pellegrino, JW. (2007). Professional development in integrating technology into teaching and learning: Knowns, unknowns, and ways to pursue better questions and answers. Review of Educational Research, 77, 575-614.
[15] National Joint Committee on Learning Disabilities (1998). Learning disabilities: Preservice preparation of general and special education teachers. Learning Disability Quarterly, 23(3), 182-186.

[16] Manning, J. B., \& Carpenter, L. B. (2008, November).Assistive technology webquest: Improving learning for preservice teachers. Retrieved February 2, 2010, from WilsonWeb.

[17] Morrison, K. (2007). Implementation of assistive computer technology: A model for school systems [Electronic version]. International Journal of Special Education, 22(1), 83-95.

[18] National Center for Education Research. (2004). Retrieved March 16, 2010, from http://nces.ed.gov/pubsearch/pubsinfo .asp?pubid=2004035

[19] National Center of Educational Research. (2007). Retrieved March 16, 2010, from http://neces.ed.gov/fastfacts/\#

[20] National Clearinghouse for English Language Acquisition. (2007). The Growing Numbers of Limited English Proficient Students. Washington, DC: Author. Retrieved January 16, 2008 from http://www.ncela.gwu.edu/policy/states/reports/st atedata/2005LEP/GrowingLEP_0506.pdf.

[21] Parette, H. P., Stoner, J. B., \& Watts, E. H. (2009).Assistive technology user group perspectives of early childhood professionals [Electronic version].Education and Training in Developmental Disabilities, 44(2), 257-270.

[22] Public Law 100-407. Technology-Related Assistance for Individuals with Disabilities Act of 1988.

[23] Puckett, K. S. (2002). Integrating assistive technology with curriculum standards.Thesis, EDRS Price MF01/PC01, Nashville.Retrieved February 2, 2010, from WilsonWeb.

[24] Sparks, D. (2006).Plugging educators into technology. Retrieved November 15, 2008 from the National Staff Development Council Web site: www.nsdc.org/library/publications/results/res2-99tech.cfm.

[25] White, E. A., Wepner, S. B., \& Wetzel, D. C. (2003, February).Accessible education through assistive technology [Electronic version].T.H.E. Journal, 24-32. 